\section{A case of acute abdominal pain}

A 30-year-old man was admitted with history of acute onset of lower abdominal pain. Abdominal examination showed tenderness over right iliac fossa. CT abdomen showed a ruptured $22 \times 40 \mathrm{~mm}$ fusiform aneurysm of right common iliac artery (CIA) and internal iliac artery (IIA) with a pseudoaneurysm of $50 \times 45 \times 40 \mathrm{~mm}$ (figure 1 ). He was taken up for an urgent endovascular procedure. Access with $7 \mathrm{~F}$ sheath through both femoral arteries was secured. Marker pig tail catheter was positioned at infrarenal aorta. A $0.358 \times 8$ MReye embolisation coil was released into the right IIA through a JR $6 \mathrm{~F}$ catheter. Then, Advanta v12 $10 \times 59$ covered stent was deployed in the right CIA across the aneurysm (figure 2). Follow-up CT angiogram showed thrombosis of the pseudoaneurysm with normal distal flow. Patient was asymptomatic at first follow-up after 1 month.

Isolated iliac artery aneurysms (IAA) are seen more in elderly men more than 60 years of age. Most (up to 70\%) occur in the CIA and two-thirds have involvement of more than one segment of the iliac arterial tree, and one-third of IAAs are

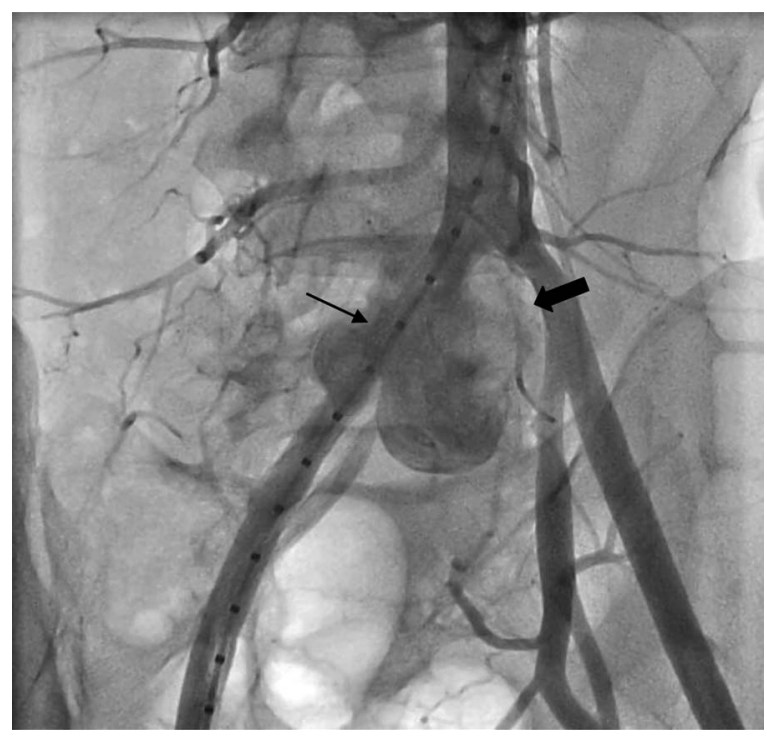

Figure 1 Descending aortogram showing aneurysm in the right common iliac artery (CIA), extending to the IIA (arrow) and the pseudoaneurysm compressing the left CIA (bold arrow).

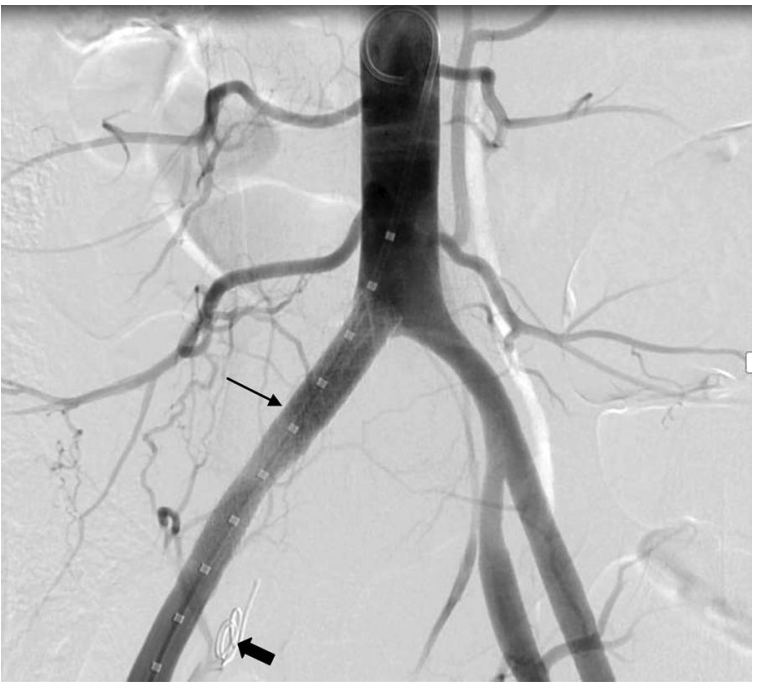

Figure 2 Descending aortogram postprocedure showing the covered stent (arrow) in right common iliac artery and external iliac artery completely excluding the aneurysm and also showing the coil in the IIA (bold arrow).

bilateral. Causes include atherosclerosis, infection, pregnancy, trauma and Marfan syndrome. Rate of rupture depends on size, and there is $31 \%$ chance of rupture if diameter is $>5.6 \mathrm{~cm} .^{1}$ Aneurysm larger than $3 \mathrm{~cm}$ is surgically repaired, but percutaneous techniques may be effective alternatives as they avoid general anaesthesia and blood loss. ${ }^{2}$ Our patient needed endovascular treatment in view of life-threatening complications, namely rupture with pseudoaneurysm formation.

Gailin Bronson Sebastian, Venketesh Radhakrishnan, Ashraf Safiya Manzil Department of Cardiology, Pariyaram Medical College, Kannur, Kerala, India

Corresponence to Dr Gailin Bronson Sebastian, Department of Cardiology, Pariyaram Medical College, Kannur 670502, Kerala, India; gailinbs@yahoo.co.in

Competing interests None.

Patient consent Obtained.

Provenance and peer review Not commissioned; internally peer reviewed. To cite Sebastian GB, Radhakrishnan V, Safiya Manzil A. Heart Asia 2013;5:203. Heart Asia 2013;5:203. doi:10.1136/heartasia-2013-010393

\section{REFERENCES}

1 Richardson JW, Greenfield LJ. Natural history and management of iliac artery aneurysm. J Vas surg 1988;8:165-71.

2 Krajcer Z, Khoshnevis R, Leachman DR, et al. Endoluminal exclusion of an iliac artery aneurysm by WallStent endoprosthesis and PTFE vascular graft. Texas Heart Inst J 1997;24:11-4. 